cambridge.org/bbs

\title{
Four things we need to know about extreme self-sacrifice-CORRIGENDUM
}

\section{Harvey Whitehouse}

\section{Corrigendum}

Cite this article: Whitehouse H. (2021) Four things we need to know about extreme selfsacrifice-CORRIGENDUM. Behavioral and Brain Sciences 44, e58: 1-1. doi:10.1017/ S0140525X21000947

https://doi.org/10.1017/S0140525X1800208X. Published by Cambridge University Press, 27 December 2018

In the Author's Response to commentaries on the target article by Whitehouse (2018), the author cited an article by Reddish et al. (2016) as showing that social synchrony increased fusion not only with co-participants but also with the extended ingroup and with the outgroup, whereas in fact the study showed that social synchrony increased prosocial (helping) behaviour towards anonymous non-performers who may be ingroup or outgroup members

\section{References}

Reddish, P., Jong, J., Lanman, J. A., Tong, E. M. W. \& Whitehouse, H. (2016). Collective synchrony increases prosociality towards non-performers and outgroup members. British Journal of Social Psychology 55(4):722-738. doi: 10.1111/bjso.12165. Whitehouse, H. (2018). Four things we need to know about extreme self-sacrifice [Author's Response]. Behavioral and Brain Sciences 41: e222. https://doi.org/10.1017/S0140525X1800208X. 